\title{
Carta de Paulo Freire aos professores
}

\author{
PAULOFREIRE
}

\section{Ensinar, aprender: leitura do mundo, leitura da palavra}

$\mathrm{N}$ ENHUM TEMA mais adequado para constituir-se em objeto desta primeira carta a quem ousa ensinar do que a significação crítica desse ato, assim como a significação igualmente crítica de aprender. É que não existe ensinar sem aprender e com isto eu quero dizer mais do que diria se dissesse que o ato de ensinar exige a existência de quem ensina e de quem aprende. Quero dizer que ensinar e aprender se vão dando de tal maneira que quem ensina aprende, de um lado, porque reconhece um conhecimento antes aprendido e, de outro, porque, observado a maneira como a curiosidade do aluno aprendiz trabalha para apreender o ensinando-se, sem o que não o aprende, o ensinante se ajuda a descobrir incertezas, acertos, equívocos.

O aprendizado do ensinante ao ensinar não se dá necessariamente através da retificação que o aprendiz lhe faça de erros cometidos. $\mathrm{O}$ aprendizado do ensinante ao ensinar se verifica à medida em que o ensinante, humilde, aberto, se ache permanentemente disponível a repensar o pensado, rever-se em suas posições; em que procura envolver-se com a curiosidade dos alunos e dos diferentes caminhos e veredas, que ela os faz percorrer. Alguns desses caminhos e algumas dessas veredas, que a curiosidade às vezes quase virgem dos alunos percorre, estão grávidas de sugestões, de perguntas que não foram percebidas antes pelo ensinante. Mas agora, ao ensinar, não como um burocrata da mente, mas reconstruindo os caminhos de sua curiosidade - razão por que seu corpo consciente, sensível, emocionado, se abre às adivinhações dos alunos, à sua ingenuidade e à sua criatividade - o ensinante que assim atua tem, no seu ensinar, um momento rico de seu aprender. $\mathrm{O}$ ensinante aprende primeiro a ensinar mas aprende a ensinar ao ensinar algo que é reaprendido por estar sendo ensinado.

O fato, porém, de que ensinar ensina o ensinante a ensinar um certo conteúdo não deve significar, de modo algum, que o ensinante se aventure a ensinar sem competência para fazê-lo. Não o autoriza a ensinar o que não sabe. A responsabilidade ética, política e profissional do ensinante lhe coloca o dever de se preparar, de se capacitar, de se formar antes mesmo de iniciar sua atividade docente. Esta atividade exige que sua preparação, sua capacitação, sua formação 
se tornem processos permanentes. Sua experiência docente, se bem percebida e bem vivida, vai deixando claro que ela requer uma formação permanente do ensinante. Formação que se funda na análise crítica de sua prática.

Partamos da experiência de aprender, de conhecer, por parte de quem se prepara para a tarefa docente, que envolve necessariamente estudar. Obviamente, minha intenção não é escrever prescrições que devam ser rigorosamente seguidas, o que significaria uma chocante contradição com tudo o que falei até agora. Pelo contrário, o que me interessa aqui, de acordo com o espírito mesmo deste livro, é desafiar seus leitores e leitoras em torno de certos pontos ou aspectos, insistindo em que há sempre algo diferente a fazer na nossa cotidianidade educativa, quer dela participemos como aprendizes, e portanto ensinantes, ou como ensinantes e, por isso, aprendizes também.

Não gostaria, assim, sequer, de dar a impressão de estar deixando absolutamente clara a questão do estudar, do ler, do observar, do reconbecer as relações entre os objetos para conhecê-los. Estarei tentando clarear alguns dos pontos que merecem nossa atenção na compreensão crítica desses processos.

Comecemos por estudar, que envolvendo o ensinar do ensinante, envolve também de um lado, a aprendizagem anterior e concomitante de quem ensina e a aprendizagem do aprendiz que se prepara para ensinar amanhã ou refaz seu saber para melhor ensinar hoje ou, de outro lado, aprendizagem de quem, criança ainda, se acha nos começos de sua escolarização.

Enquanto preparação do sujeito para aprender, estudar é, em primeiro lugar, um que-fazer crítico, criador, recriador, não importa que eu nele me engaje através da leitura de um texto que trata ou discute um certo conteúdo que me foi proposto pela escola ou se o realizo partindo de uma reflexão crítica sobre um certo acontecimentos social ou natural e que, como necessidade da própria reflexão, me conduz à leitura de textos que minha curiosidade e minha experiência intelectual me sugerem ou que me são sugeridos por outros.

Assim, em nível de uma posição crítica, a que não dicotomiza o saber do senso comum do outro saber, mais sistemático, de maior exatidão, mas busca uma síntese dos contrários, o ato de estudar implica sempre o de ler, mesmo que neste não se esgote. De ler o mundo, de ler a palavra e assim ler a leitura do mundo anteriormente feita. Mas ler não é puro entretenimento nem tampouco um exercício de memorização mecânica de certos trechos do texto.

Se, na verdade, estou estudando e estou lendo seriamente, não posso ultrapassar uma página se não consegui com relativa clareza, ganhar sua significação. Minha saída não está em memorizar porções de períodos lendo mecanicamente duas, três, quatro vezes pedaços do texto fechando os olhos e tentando repeti-las como se sua fixação puramente maquinal me desse o conhecimento de que preciso. 
Ler é uma operação inteligente, difícil, exigente, mas gratificante. Ninguém lê ou estuda autenticamente se não assume, diante do texto ou do objeto da curiosidade a forma crítica de ser ou de estar sendo sujeito da curiosidade, sujeito da leitura, sujeito do processo de conhecer em que se acha. Ler é procurar buscar criar a compreensão do lido; daí, entre outros pontos fundamentais, a importância do ensino correto da leitura e da escrita. É que ensinar a ler é engajar-se numa experiência criativa em torno da compreensão. Da compreensão e da comunicação.

E a experiência da compreensão será tão mais profunda quanto sejamos nela capazes de associar, jamais dicotomizar, os conceitos emergentes da experiência escolar aos que resultam do mundo da cotidianidade. Um exercício crítico sempre exigido pela leitura e necessariamente pela escuta é o de como nos darmos facilmente à passagem da experiência sensorial que caracteriza a cotidianidade à generalização que se opera na linguagem escolar e desta ao concreto tangível. Uma das formas de realizarmos este exercício consiste na prática que me venho referindo como "leitura da leitura anterior do mundo", entendendo-se aqui como "leitura do mundo" a "leitura" que precede a leitura da palavra e que perseguindo igualmente a compreensão do objeto se faz no domínio da cotidianidade. A leitura da palavra, fazendo-se também em busca da compreensão do texto e, portanto, dos objetos nele referidos, nos remete agora à leitura anterior do mundo. O que me parece fundamental deixar claro é que a leitura do mundo que é feita a partir da experiência sensorial não basta. Mas, por outro lado, não pode ser desprezada como inferior pela leitura feita a partir do mundo abstrato dos conceitos que vai da generalização ao tangível.

Certa vez, uma alfabetizanda nordestina discutia, em seu círculo de cultura, uma codificação (1) que representava um homem que, trabalhando o barro, criava com as mãos, um jarro. Discutia-se, através da "leitura" de uma série de codificações que, no fundo, são representações da realidade concreta, o que é cultura. O conceito de cultura já havia sido apreendido pelo grupo através do esforço da compreensão que caracteriza a leitura do mundo e/ou da palavra. $\mathrm{Na}$ sua experiência anterior, cuja memória ela guardava no seu corpo, sua compreensão do processo em que o homem, trabalhando o barro, criava o jarro, compreensão gestada sensorialmente, lhe dizia que fazer o jarro era uma forma de trabalho com que, concretamente, se sustentava. Assim como o jarro era apenas o objeto, produto do trabalho que, vendido, viabilizava sua vida e a de sua família.

Agora, ultrapassando a experiência sensorial, indo mais além dela, dava um passo fundamental: alcançava a capacidade de generalizar que caracteriza a "experiência escolar". Criar o jarro como o trabalho transformador sobre o barro não era apenas a forma de sobreviver, mas também de fazer cultura, de fazer arte. Foi por isso que, relendo sua leitura anterior do mundo e dos que-fazeres no mundo, aquela alfabetizanda nordestina disse segura e orgulhosa: "Faço cultura. Faço isto". 
Paulo Reglus Neves Freire nasceu no dia 19 de setembro de 1921 em Recife, Pernambuco. Aprendeu a ler e a escrever com os pais, à sombra das árvores do quintal da casa em que nasceu. Tinha oito anos quando a família teve que se mudar para Jaboatão, a 18 $\mathrm{km}$ de Recife. Aos 13 anos perdeu o pai e seus estudos tiveram que ser adiados. Entrou no ginásio com 16 anos. Aos 20 conseguiu uma vaga na Faculdade de Direito do Recife.

O estudo da linguagem do povo foi um dos pontos de partida da elaboração pedagógica de Paulo Freire, para o que também foi muito significativo o seu envolvimento com o Movimento de Cultura Popular (MCP) do Recife. Foi um dos fundadores do Serviço de Extensão Cultural da Universidade do Recife e seu primeiro diretor. Através desse trabalho elaborou os primeiros estudos de um novo método de alfabetização, que expôs em 1958. As primeiras experiências do Método Paulo Freire começaram na cidade de Angicos,

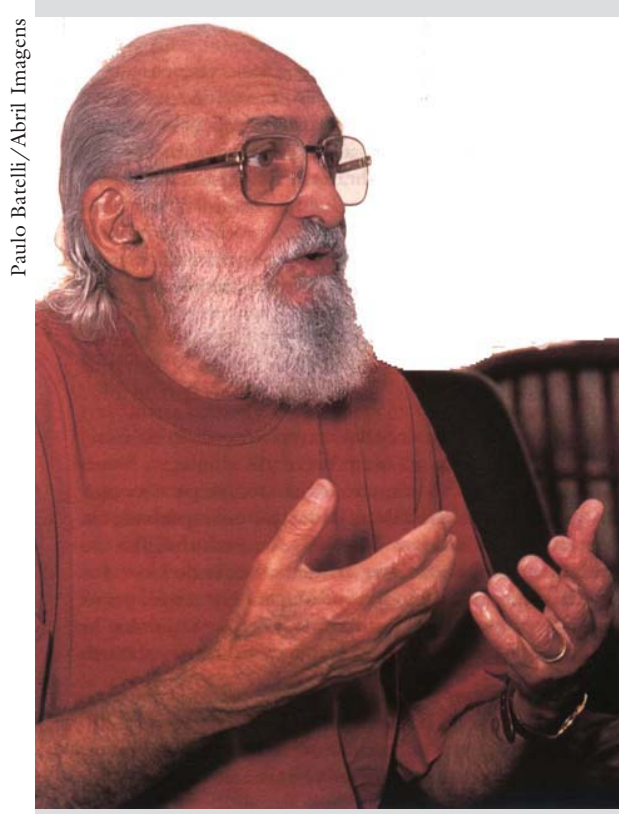

Paulo Freire (1921-1997) no Rio Grande do Norte, em 1962, onde 300 trabalhadores foram alfabetizados em 45 dias. No ano seguinte, foi convidado pelo presidente João Goulart para repensar a alfabetização de adultos em âmbito nacional. O golpe militar interrompeu os trabalhos e reprimiu toda a mobilização popular.

Paulo Freire foi preso, acusado de comunista. Foram 16 anos de exílio, dolorosos, mas também muito produtivos: uma estadia de cinco anos no Chile como consultor da Unesco no Instituto de Capacitação e Investigação em Reforma Agrária; uma mudança para Genebra, na Suíça em 1970, para trabalhar como consultor do Conselho Mundial de Igejas, onde desenvolveu programas de alfabetização para a Tanzânia e Guiné-Bissau, e ajudou em campanhas no Peru e Nicaraguá; em 1980, voltou definitivamente ao país, passando a ser professor da PUCSP e da Univesidade de Campinas (Unicamp). Uma das experiências significativas de Paulo Freire foi ter trabalhado como secretário da Educação da Prefeitura de São Paulo, na gestão Luiza Erundina (PT), entre 1989 e 1991. Paulo Freire morreu no dia 2 de maio de 1997, aos 76 anos de idade, em plena atividade de educador e de pensador. Estava casado com Ana Maria (Nita) Araújo Freire, também educadora.

É autor dos livros Educação como prática da libedade. Rio de Janeiro, Paz e Terra, 1967; Pedagogia do oprimido. Rio de Janeiro, Paz e Terra, 1970; Extensão ou comunicação? Rio de Janeiro, Paz e Terra, 1971; Ação cultural para a liberdade e outros escritos. Rio de Janeiro, Paz e Terra, 1976; Cartas à Guiné-Bissau. Registros de uma experiência em processo. Rio de Janeiro, Paz e Terra, 1977; Educação e mudança. Rio de Janeiro, Paz e Terra, 1979; A importância do ato de ler em três artigos que se completam. São Paulo, Cortez, 1982; A Educação na cidade. São Paulo, Cortez, 1991; Pedagogia da esperança: um reencontro com a Pedagogia do Oprimido. Rio de Janeiro, Paz e Terra, 1992; Política e educação. São Paulo, Cortez, 1993; Professora sim, Tia não: cartas a quem ousa ensinar. São Paulo, Olho D’Água, 1993; Cartas a Cristina. Rio de Janeiro, Paz e Terra, 1994; À sombra desta mangueira. São Paulo, Olho D’Água, 1995. Pedagogia de autonomia. Rio de Janeiro, Paz e Terra, 1996. Pedagogia da indignação. São Paulo, Editora da Unesp, 2000. 
Noutra ocasião presenciei experiência semelhante do ponto de vista da inteligência do comportamento das pessoas. Já me referi a este fato em outro trabalho mas não faz mal que o retome agora. Me achava na Ilha de São Tomé, na África Ocidental, no Golfo da Guiné. Participava com educadores e educadoras nacionais, do primeiro curso de formação para alfabetizadores.

Havia sido escolhido pela equipe nacional um pequeno povoado, Porto Mont, região de pesca, para ser o centro das atividades de formação. Havia sugerido aos nacionais que a formação dos educadores e educadoras se fizesse não seguindo certos métodos tradicionais que separam prática de teoria. Nem tampouco através de nenhuma forma de trabalho essencialmente dicotomizante de teoria e prática e que ou menospreza a teoria, negando-lhe qualquer importância, enfatizando exclusivamente a prática, a única a valer, ou negando a prática fixando-se só na teoria. Pelo contrário, minha intenção era que, desde o começo do curso, vivêssemos a relação contraditória entre prática e teoria, que será objeto de análise de uma de minhas cartas.

Recusava, por isso mesmo, uma forma de trabalho em que fossem reservados os primeiros momentos do curso para exposições ditas teóricas sobre matéria fundamental de formação dos futuros educadores e educadoras. Momento para discursos de algumas pessoas, as consideradas mais capazes para falar aos outros.

Minha convicção era outra. Pensava numa forma de trabalho em que, numa única manhã, se falasse de alguns conceitos-chave - codificação, decodificação, por exemplo - como se estivéssemos num tempo de apresentações, sem, contudo, nem de longe imaginar que as apresentações de certos conceitos fossem já suficientes para o domínio da compreensão em torno deles. A discussão crítica sobre a prática em que se engajariam é o que o faria.

Assim, a idéia básica, aceita e posta em prática, é que os jovens que se preparariam para a tarefa de educadoras e educadores populares deveriam coordenar a discussão em torno de codificações num círculo de cultura com 25 participantes. Os participantes do círculo de cultura estavam cientes de que se tratava de um trabalho de afirmação de educadores. Discutiu-se com eles antes sua tarefa política de nos ajudar no esforço de formação, sabendo que iam trabalhar com jovens em pleno processo de sua formação. Sabiam que eles, assim como os jovens a serem formados, jamais tinham feito o que iam fazer. A única diferença que os marcava é que os participantes liam apenas o mundo enquanto os jovens a serem formados para a tarefa de educadores liam já a palavra também. Jamais, contudo, haviam discutido uma codificação assim como jamais haviam tido a mais mínima experiência alfabetizando alguém.

Em cada tarde do curso com duas horas de trabalho com os 25 participantes, quatro candidatos assumiam a direção dos debates. Os responsáveis pelo curso 
assistiam em silêncio, sem interferir, fazendo suas notas. No dia seguinte, no seminário de avaliação de formação, de quatro horas, se discutiam os equívocos, os erros e os acertos dos candidatos, na presença do grupo inteiro, desocultandose com eles a teoria que se achava na sua prática.

Dificilmente se repetiam os erros e os equívocos que haviam sido cometidos e analisados. A teoria emergia molhada da prática vivida.

Foi exatamente numa das tardes de formação que, durante a discussão de uma codificação que retratava Porto Mont, com suas casinhas alinhadas à margem da praia, em frente ao mar, com um pescador que deixava seu barco com um peixe na mão, que dois dos participantes, como se houvessem combinado, se levantaram, andaram até a janela da escola em que estávamos e olhando Porto Mont lá longe, disseram, de frente novamente para a codificação que representava o povoado: "É. Porto Mont é assim e não sabíamos".

Até então, sua "leitura" do lugarejo, de seu mundo particular, uma "leitura" feita demasiadamente próxima do "texto", que era o contexto do povoado, não lhes havia permitido ver Porto Mont como ele era. Havia uma certa "opacidade" que cobria e encobria Porto Mont. A experiência que estavam fazendo de "tomar distância" do objeto, no caso, da codificação de Porto Mont, lhes possibilitava uma nova leitura mais fiel ao "texto", quer dizer, ao contexto de Porto Mont. A "tomada de distância" que a "leitura" da codificação lhes possibilitou os aproximou mais de Porto Mont como "texto" sendo lido. Esta nova leitura refez a leitura anterior, daí que hajam dito: "É. Porto Mont é assim e não sabíamos". Imersos na realidade de seu pequeno mundo, não eram capazes de vê-la. "Tomando distância" dela, emergiram e, assim, a viram como até então jamais a tinham visto.

Estudar é desocultar, é ganhar a compreensão mais exata do objeto, é perceber suas relações com outros objetos. Implica que o estudioso, sujeito do estudo, se arrisque, se aventure, sem o que não cria nem recria.

Por isso também é que ensinar não pode ser um puro processo, como tanto tenho dito, de transferência de conhecimento do ensinante ao aprendiz. Transferência mecânica de que resulte a memorização maquinal que já critiquei. Ao estudo crítico corresponde um ensino igualmente crítico que demanda necessariamente uma forma crítica de compreender e de realizar a leitura da palavra e a leitura do mundo, leitura do contexto.

A forma crítica de compreender e de realizar a leitura da palavra e a leitura do mundo está, de um lado, na não negação da linguagem simples, "desarmada", ingênua, na sua não desvalorização por constituir-se de conceitos criados na cotidianidade, no mundo da experiência sensorial; de outro, na recusa ao que se chama de "linguagem difícil", impossível, porque desenvolvendo-se em torno 
de conceitos abstratos. Pelo contrário, a forma crítica de compreender e de realizar a leitura do texto e a do contexto não exclui nenhuma da duas formas de linguagem ou de sintaxe. Reconhece, todavia, que o escritor que usa a linguagem científica, acadêmica, ao dever procurar tornar-se acessível, menos fechado, mais claro, menos difícil, mais simples, não pode ser simplista.

Ninguém que lê, que estuda, tem o direito de abandonar a leitura de um texto como difícil porque não entendeu o que significa, por exemplo, a palavra epistemologia.

Assim como um pedreiro não pode prescindir de um conjunto de instrumentos de trabalho, sem os quais não levanta as paredes da casa que está sendo construída, assim também o leitor estudioso precisa de instrumentos fundamentais, sem os quais não pode ler ou escrever com eficácia. Dicionários (2), entre eles o etimológico, o de regimes de verbos, o de regimes de substantivos e adjetivos, o filosófico, o de sinônimos e de antônimos, enciclopédias. A leitura comparativa de texto, de outro autor que trate o mesmo tema cuja linguagem seja menos complexa.

Usar esses instrumentos de trabalho não é, como às vezes se pensa, uma perda de tempo. O tempo que eu uso quando leio ou escrevo ou escrevo e leio, na consulta de dicionários e enciclopédias, na leitura de capítulos, ou trechos de livros que podem me ajudar na análise mais crítica de um tema - é tempo fundamental de meu trabalho, de meu ofício gostoso de ler ou de escrever.

Enquanto leitores, não temos o direito de esperar, muito menos de exigir, que os escritores façam sua tarefa, a de escrever, e quase a nossa, a de compreender o escrito, explicando a cada passo, no texto ou numa nota ao pé da página, o que quiseram dizer com isto ou aquilo. Seu dever, como escritores, é escrever simples, escrever leve, é facilitar e não dificultar a compreensão do leitor, mas não dar a ele as coisas feitas e prontas.

A compreensão do que se está lendo, estudando, não estala assim, de repente, como se fosse um milagre. A compreensão é trabalhada, é forjada, por quem lê, por quem estuda que, sendo sujeito dela, se deve instrumentar para melhor fazê-la. Por isso mesmo, ler, estudar, é um trabalho paciente, desafiador, persistente.

Não é tarefa para gente demasiado apressada ou pouco humilde que, em lugar de assumir suas deficiências, as transfere para o autor ou autora do livro, considerado como impossível de ser estudado.

É preciso deixar claro, também, que há uma relação necessária entre o nível do conteúdo do livro e o nível da atual formação do leitor. Estes níveis envolvem a experiência intelectual do autor e do leitor. A compreensão do que se lê tem que ver com essa relação. Quando a distância entre aqueles níveis é demasiado 
grande, quanto um não tem nada que ver com o outro, todo esforço em busca da compreensão é inútil. Não está havendo, neste caso, uma consonância entre o indispensável tratamento dos temas pelo autor do livro e a capacidade de apreensão por parte do leitor da linguagem necessária àquele tratamento. Por isso mesmo é que estudar é uma preparação para conhecer, é um exercício paciente e impaciente de quem, não pretendendo tudo de uma vez, luta para fazer a vez de conhecer.

A questão do uso necessário de instrumentos indispensáveis à nossa leitura e ao nosso trabalho de escrever levanta o problema do poder aquisitivo do estudante e das professoras e professores em face dos custos elevados para obter dicionários básicos da língua, dicionários filosóficos etc. Poder consultar todo esse material é um direito que têm alunos e professores a que corresponde o dever das escolas de fazer-lhes possível a consulta, equipando ou criando suas bibliotecas, com horários realistas de estudo. Reivindicar esse material é um direito e um dever de professores e estudantes.

Gostaria de voltar a algo a que fiz referência anteriormente: a relação entre ler e escrever, entendidos como processos que não se podem separar. Como processos que se devem organizar de tal modo que ler e escrever sejam percebidos como necessários para algo, como sendo alguma coisa de que a criança, como salientou Vygotsky (3), necessita e nós também.

Em primeiro lugar, a oralidade precede a grafia mas a traz em si desde o primeiro momento em que os seres humanos se tornaram socialmente capazes de ir exprimindo-se através de símbolos que diziam algo de seus sonhos, de seus medos, de sua experiência social, de suas esperanças, de suas práticas.

Quando aprendemos a ler, o fazemos sobre a escrita de alguém que antes aprendeu a ler e a escrever. Ao aprender a ler, nos preparamos para imediatamente escrever a fala que socialmente construímos.

Nas culturas letradas, sem ler e sem escrever, não se pode estudar, buscar conhecer, apreender a substantividade do objeto, reconhecer criticamente a razão de ser do objeto.

Um dos equívocos que cometemos está em dicotomizar ler de escrever, desde o começo da experiência em que as crianças ensaiam seus primeiros passos na prática da leitura e da escrita, tomando esses processos como algo desligado do processo geral de conhecer. Essa dicotomia entre ler e escrever nos acompanha sempre, como estudantes e professores. "Tenho uma dificuldade enorme de fazer minha dissertação. Não sei escrever", é a afirmação comum que se ouve nos cursos de pós-graduação de que tenho participado. No fundo, isso lamentavelmente revela o quanto nos achamos longe de uma compreensão crítica do que é estudar e do que é ensinar. 
É preciso que nosso corpo, que socialmente vai se tornando atuante, consciente, falante, leitor e "escritor" se aproprie criticamente de sua forma de vir sendo que faz parte de sua natureza, histórica e socialmente constituindo-se. Quer dizer, é necessário que não apenas nos demos conta de como estamos sendo mas nos assumamos plenamente com estes "seres programados, mas para aprender”, de que nos fala François Jacob (4). É necessário, então, que aprendamos a aprender, vale dizer, que entre outras coisas, demos à linguagem oral e escrita, a seu uso, a importância que lhe vem sendo cientificamente reconhecida.

Aos que estudamos, aos que ensinamos e, por isso, estudamos também, se nos impõe, ao lado da necessária leitura de textos, a redação de notas, de fichas de leitura, a redação de pequenos textos sobre as leituras que fazemos. A leitura de bons escritores, de bons romancistas, de bons poetas, dos cientistas, dos filósofos que não temem trabalhar sua linguagem a procura da boniteza, da simplicidade e da clareza (5).

Se nossas escolas, desde a mais tenra idade de seus alunos se entregassem ao trabalho de estimular neles o gosto da leitura e o da escrita, gosto que continuasse a ser estimulado durante todo o tempo de sua escolaridade, haveria possivelmente um número bastante menor de pós-graduandos falando de sua insegurança ou de sua incapacidade de escrever.

Se estudar, para nós, não fosse quase sempre um fardo, se ler não fosse uma obrigação amarga a cumprir, se, pelo contrário, estudar e ler fossem fontes de alegria e de prazer, de que resulta também o indispensável conhecimento com que nos movemos melhor no mundo, teríamos índices melhor reveladores da qualidade de nossa educação.

Este é um esforço que deve começar na pré-escola, intensificar-se no período da alfabetização e continuar sem jamais parar.

A leitura de Piaget, de Vygotsky, de Emilia Ferreiro, de Madalena F. Weffort, entre outros, assim como a leitura de especialistas que tratam não propriamente da alfabetização mas do processo de leitura como Marisa Lajolo e Ezequiel T. da Silva é de indiscutível importância.

Pensando na relação de intimidade entre pensar, ler e escrever e na necessidade que temos de viver intensamente essa relação, sugeriria a quem pretenda rigorosamente experimentá-la que, pelo menos, três vezes por semana, se entregasse à tarefa de escrever algo. Uma nota sobre uma leitura, um comentário em torno de um acontecimento de que tomou conhecimento pela imprensa, pela televisão, não importa. Uma carta para destinatário inexistente. É interessante datar os pequenos textos e guardá-los e dois ou três meses depois submetê-los a uma avaliação crítica.

Ninguém escreve se não escrever, assim como ninguém nada se não nadar. 
Ao deixar claro que o uso da linguagem escrita, portanto o da leitura, está em relação com o desenvolvimento das condições materiais da sociedade, estou sublimando que minha posição não é idealista.

Recusando qualquer interpretação mecanicista da História, recuso igualmente a idealista. A primeira reduz a consciência à pura cópia das estruturas materiais da sociedade; a segunda submete tudo ao todo poderosismo da consciência. Minha posição é outra. Entendo que estas relações entre consciência e mundo são dialéticas (6).

O que não é correto, porém, é esperar que as transformações materiais se processem para que depois comecemos a encarar corretamente o problema da leitura e da escrita.

A leitura crítica dos textos e do mundo tem que ver com a sua mudança em processo.

Notas

1 Sobre codificação, leitura do mundo-leitura da palavra-senso comum-conhecimento exato, aprender, ensinar, veja-se: Freire, Paulo: Educação como prática da liberdade Educação e mudança - Ação cultural para a liberdade - Pedagogia do oprimido Pedagogia da esperança, Paz e Terra; Freire \& Sérgio Guimarães, Sobre educação, Paz e Terra; Freire \& Ira Schor, Medo e ousadia, o cotidiano do educador, Paz e Terra; Freire \& Donaldo Macedo, Alfabetização, leitura do mundo e leitura da palavra, Paz e Terra; Freire, Paulo, A importância do ato de ler, Cortez. Freire \& Márcio Campos; Leitura do mundo - Leitura da palavra, Courrier de L'Unesco, fev. 1991.

2 Ver Freire, Paulo. Pedagogia da esperança-um reencontro com a Pedagogia do oprimido, Paz e Terra, 1992.

3 Vygotsky and education. Instructional implications and applications of sociohistorical psychology. Luis C. Moll (ed.), Cambridge University Press, First paper back edition, 1992.

4 François Jacob, Nous sommes programmés mais pour aprendre. Le Courrier de L'Unesco, Paris, fev. 1991.

5 Ver Freire, Paulo, Pedagogia da esperança, Paz e Terra, 1992.

6 Id., ibid.

Esta carta foi retirada do livro Professora sim, tia não. Cartas a quem ousa ensinar (Editora Olho D'Água, 10ª ed., p. 27-38) no qual Paulo Freire dialoga sobre questões da construção de uma escola democrática e popular. Escreve especialmente aos professores, convocando-os ao engajamento nesta mesma luta. Este livro foi escrito durante dois meses do ano de 1993, pouco tempo depois de sua experiência na condução da Secretaria de Educação de São Paulo. 